\title{
Business Model Risk Analysis: Predicting the Probability of Business Network Profitability
}

\author{
Pontus Johnson ${ }^{1}$, Maria Eugenia Iacob ${ }^{2}$, Margus Välja ${ }^{1}$, Marten van Sinderen ${ }^{2}$, \\ Christer Magnusson ${ }^{3}$, and Tobias Ladhe ${ }^{3}$ \\ ${ }^{1}$ Department of Industrial Information and Control Systems \\ Royal Institute of Technology (KTH), Stockholm, Sweden \\ ${ }^{2}$ Centre for Telematics and Information Technology, \\ University of Twente, Enschede, The Netherlands \\ ${ }^{3}$ Department of Computer and Systems Sciences \\ Stockholm University, Stockholm, Sweden \\ \{pontusj, margus.valja\} @ics.kth.se, \\ \{m.e.iacob,m.j.vansinderen\}@utwente.nl, \{ladhe, cmagnus\}@dsv.su.se
}

\begin{abstract}
In the design phase of business collaboration, it is desirable to be able to predict the profitability of the business-to-be. Therefore, techniques to assess qualities such as costs, revenues, risks, and profitability have been previously proposed. However, they do not allow the modeler to properly manage uncertainty with respect to the design of the considered business collaboration. In many real collaboration projects today, uncertainty regarding the business' present or future characteristics is so significant that ignoring it becomes problematic. In this paper, we propose an approach based on the Predictive, Probabilistic Architecture Modeling Framework $\left(\mathrm{P}^{2} \mathrm{AMF}\right)$, capable of advanced and probabilistically sound reasoning about profitability risks. The $\mathrm{P}^{2} \mathrm{AMF}-$ based approach for profitability risk prediction is also based on the $\mathrm{e}^{3}$-value modeling language and on the Object Constraint Language (OCL). The paper introduces the prediction and modeling approach, and a supporting software tool. The use of the approach is illustrated by means of a case.
\end{abstract}

Keywords: value networks, profitability, risk analysis, probabilistic inference, goal interoperability.

\section{Introduction}

A business model is critical for any new business venture, and especially for those that involve multiple organizations, due to the complexity of their relationships. In the literature of the last decade several authors have proposed different frameworks aimed at identifying the main ingredients of a business model (e.g., [20,21]; for an overview, see $[19,18])$. An important motivation behind business modeling is its ability to provide an overview of the relationships between the actors involved in a business collaboration and of the way they all aim to benefit from it, financially or otherwise.

In the design phase of a business collaboration, it is desirable to be able to predict the risks concerning profitability associated with the "business-to-be". As an 
alternative to the rather costly trial-and-error approach, it is desirable to understand the properties of the envisioned collaboration already in its early phases. Therefore some of the existing business modeling approaches not only model the business, but also propose some techniques to assess qualities such as costs and revenues [20], and profitability [21]. However, they do not allow the modeler to properly express uncertainty with respect to the considered business collaboration. In many real collaboration projects today, uncertainty regarding the business' present or future characteristics is so significant that ignoring it becomes problematic.

Our main contribution in this paper is an approach capable of advanced and probabilistically sound reasoning about profitability risks of a given business model expressed in the $\mathrm{e}^{3}$-value modeling language [21]. Such predictions may guide business managers, allowing them to explore and compare collaboration scenario alternatives at a low cost. Profitability predictions do, in fact, constitute an important element in the strategic decision making process, and a critical part of the assessment of risks associated with a new business venture. Managers routinely argue for or against alternative business opportunities based on those opportunities' expected impact on, e.g., the company's future financial and business performance. However, experience/intuition-based predictions made by individual managers have serious drawbacks in terms of transparency, consistency, and ability to correctly evaluate costs and risks. Therefore, formal approaches to business model quality prediction are required. They not only allow us to anticipate the business-to-be, but they are also a means to achieve pragmatic and, goal interoperability [30] in multi-actor business collaborations.

The proposed profitability prediction approach draws upon our earlier work concerning the Predictive, Probabilistic Architecture Modeling Framework $\left(\mathrm{P}^{2} \mathrm{AMF}\right)$ [4] that, in turn, is based on the Object Constraint Language (OCL) [17]. The process we follow to develop our profitability prediction approach is as follows. In the first step, starting from the original definition of the $\mathrm{e}^{3}$-value ontology, we define the $\mathrm{e}^{3}$ value metamodel in the $\mathrm{P}^{2} \mathrm{AMF}$, expressed as an OCL-annotated class diagram. Consequently, any $\mathrm{e}^{3}$-value model can be instantiated from the $\mathrm{e}^{3}$-value class diagram metamodel in the form of an object diagram. Finally, we define and implement the underlying inference algorithm for the prediction of the attribute values associated with the model elements of the object model. Thus, the execution of the inference algorithm produces, for example, predictions about the net earnings attribute values for all actors participating in a business collaboration. Such profitability predictions of each of the actors involved, are determined taking into account given levels of uncertainty (expressed as probability distributions) at three levels: uncertainty regarding attribute values of objects in the object model, uncertainty related to objects (e.g., uncertainties regarding the actors' participation in the value network), and uncertainties regarding the (existence of) relationships between objects (e.g., uncertainties related to a value exchange). This represents an important advancement compared to Gordijn's work on profitability sheets and analysis [21], since Gordijn's approach only considers deterministic values for attributes, and value network models are fixed. Furthermore, due to the fact that the P2AMF and the EAAT allow us to incorporate uncertainty in $\mathrm{e}^{3}$-value models, profitability predictions can be seen as 
risk assessments. To the best of our knowledge, this is the first time a formal business model-based profitability risk analysis method is proposed for business models. Work on how trust assumptions affect profitability in value networks has been reported (e.g., [24]). However, it should be noted that trust is just one specific source of risk.

The remainder of this paper is organized as follows. In Section 2 we briefly present the original $\mathrm{e}^{3}$-value business model ontology [21]. Section 3 is devoted to the $\mathrm{P}^{2} \mathrm{AMF}$ and tool. Section 4 describes the main contribution of this paper, the profitability prediction approach and illustrates the usage of this approach by means of the electric cars case study that has been defined in the scope of the Stockholm Royal Seaport Smart City project [29]. The papers ends with some conclusions and pointers to future work.

\section{Business Modeling and the $\mathrm{e}^{3}$-Value Ontology}

In this section we motivate our choice for the $\mathrm{e}^{3}$-value modeling formalism and briefly present the $\mathrm{e}^{3}$-value ontology [21].

Many business model frameworks exist that aim at facilitating and guiding business modeling, e.g., Activity system [16], e $e^{3}$-value [21], VDML [26], REA [27], RCOV [14], The BM concept [10], Entrepreneur's BM [13], The social BM [15], The $B M$ guide [9], 4C [11], Internet BM [12], and BMO [20]. Some of them have a strong link to information systems, others are closely related to strategic management or industrial organization. Most of the business model frameworks mentioned above have been published in the top 25 MIS journals. However, a systematic literature review we carried out recently [18] resulted in an initial set of 171 journal articles and conference papers relevant for the topic of business modeling. After filtering this set of publications, we ended up with 76 articles presenting some 43 different business model frameworks. Furthermore, five articles in the reviewed literature present a review of business model literature and aim to compare some existing frameworks: $[19,5,7,6,8]$. A common trait of most of these frameworks is that they lack the level of formality which is necessary to relate a business model to its supporting enterprise architecture at the model level. However, of the reviewed frameworks, two stand out as having, from the modeling point of view, a sufficient formal foundation: $\mathrm{e}^{3}$-value [21] and BMO [20]. An extensive comparison of these two formalisms is presented in [5]. There are some significant differences between the two approaches. In terms of the scope covered, BMC is focused on a single element of a value chain and its direct relations with customers and suppliers, while $\mathrm{e}^{3}$-value takes a network perspective in order to provide insight into value generation outside the formal boundary of a single organization. Also, at the conceptual level they are quite different: the BMO puts emphasis on resources needed to create a certain value proposition, while in $\mathrm{e}^{3}$-value, the modeling of value streams in a business network is central. An approximate mapping between $\mathrm{BMO}$ and $\mathrm{e}^{3}$-value concepts is proposed in [5], which clearly reveals these differences. When considering the level of formality, although both $\mathrm{e}^{3}-$ value and BMO have been found to be "light weight" ontologies [5], $\mathrm{e}^{3}$-value is more formal than BMO since it comes with a metamodel [22] and a graphical notation, for 
which reason it is also a modeling language. The fact that BMC is widely accepted is partly due to its simplicity and ease of use, which come at the cost of formality. In this paper we choose for $\mathrm{e}^{3}$-value because of its higher level of formalism and because it provides a network perspective on business collaborations which makes it suitable for capturing network effects regarding value propagation.

In the remainder of this section we briefly summarize the $\mathrm{e}^{3}$-value modeling constructs (for more details we refer to $[22,21]$ ). An $\mathrm{e}^{3}$-value model essentially describes the value exchange relationships between two or more actors involved in a business collaboration, expressed as a value network model. The main concepts defined in the $\mathrm{e}^{3}$-value business model ontology that capture these exchanges are: actor (with its specializations, market segment and composed actor), value exchange, value object, value port, and the value interface. Besides a structural specification of the elements of a business value network and of its value streams, an $\mathrm{e}^{3}$-value model also captures behavioral aspects of such networks with respect to the flow of value. As such, concepts such as stimulus and end stimulus, dependency path and value exchange are used to define a so-called use case map describing the business behavior of actor in the collaboration modeled by the $\mathrm{e}^{3}$-value model. In Table 1 below we summarize the definition of all these concepts, and their graphical notation. Furthermore, in Figure 2 an example of an $\mathrm{e}^{3}$-value model can be seen.

\section{The $\mathbf{P}^{2}$ AMF}

As mentioned before, we use the $\mathrm{P}^{2} \mathrm{AMF}$ framework [4] and the Enterprise Architecture Analysis Tool (EAAT) [3] tool to extend $\mathrm{e}^{3}$-value to a probabilistic setting. $\mathrm{P}^{2} \mathrm{AMF}$ is based on the Object Constraint Language (OCL) [17], which is a formal language used to describe expressions on models in the Unified Modeling Language (UML). OCL expressions typically specify invariant conditions that must hold for the system being modeled or queries over objects described in a model. The most prominent difference between $\mathrm{P}^{2} \mathrm{AMF}$ and OCL is the probabilistic nature of $\mathrm{P}^{2} \mathrm{AMF}$. $\mathrm{P}^{2} \mathrm{AMF}$ allows the user to capture uncertainties in both attribute values and model structure.

Table 1. $\mathrm{e}^{3}$-value concepts

\begin{tabular}{|l|l|l|}
\hline Concept & Definition & Notation \\
\hline actor & $\begin{array}{l}\text { "an economically independent (and often also legal) } \\
\text { entity" [21] }\end{array}$ & $\begin{array}{l}\text { Mactor } \\
\text { Market } \\
\text { segment } \\
\text { used to model that there is a large group of end- } \\
\text { consumers who value objects similarly. }\end{array}$ \\
\hline Value interface & $\begin{array}{l}\text { Used to groups one or more value ports of one actor. } \\
\text { Value port }\end{array}$ & $\begin{array}{l}\text { "An actor uses a value port to provide or request value } \\
\text { objects to or from his/her environment, consisting of } \\
\text { other actors. Thus, a value port is used to interconnect } \\
\text { actors so that they are able to exchange value objects." } \\
\text { [21] }\end{array}$ \\
\hline
\end{tabular}


Table 1. (continued)

\begin{tabular}{|l|l|l|}
\hline $\begin{array}{l}\text { Value } \\
\text { exchange }\end{array}$ & $\begin{array}{l}\text { "Is used to connect two value ports with each other. It } \\
\text { represents one or more potential trades of value object } \\
\text { instances between value ports. As such, it is a prototype } \\
\text { for actual trades between actors. [... It does not model } \\
\text { actual exchanges of value object instances." [21] }\end{array}$ \\
\hline $\begin{array}{l}\text { Value } \\
\text { transaction }\end{array}$ & $\begin{array}{l}\text { "Concept that aggregates all value exchanges, which } \\
\text { define the value exchange instances that must occur as } \\
\text { consequence of how value exchanges are connected, via } \\
\text { value interfaces to actors." [21] }\end{array}$ & $\begin{array}{l}\text { No distinct notation is } \\
\text { defined in the tool. }\end{array}$ \\
\hline Value object & $\begin{array}{l}\text { "A service, a product, or even an experience, which is } \\
\text { of economic value for at least one of the actors involved } \\
\text { in a value model" [21] }\end{array}$ & $\begin{array}{l}\text { Is represented as a label } \\
\text { on a value exchange } \\
\text { relationship. }\end{array}$ \\
\hline $\begin{array}{l}\text { Value activity } \\
\text { And/Or fork } \\
\text { and join }\end{array}$ & $\begin{array}{l}\text { Collection of operational activities, which can be } \\
\text { assigned as a whole to an actor and lead to creation of } \\
\text { profit or economic value for the performing actor. [21] }\end{array}$ & $\begin{array}{l}\text { An AND fork connects a scenario element to one or } \\
\text { more other elements, while the AND join connects one } \\
\text { or more elements to one other element. An OR fork } \\
\text { models a continuation of the scenario path into one } \\
\text { direction, to be chosen from a number of alternatives. } \\
\text { The OR join merges two or paths into one. [21] }\end{array}$ \\
\hline $\begin{array}{l}\text { Start and end } \\
\text { stimuli }\end{array}$ & $\begin{array}{l}\text { start stimulus represents an event, possibly caused by an } \\
\text { actor. [...] A use case map also has one or more end } \\
\text { stimuli. They have no successors." [21] }\end{array}$ \\
\hline
\end{tabular}

\subsection{An Introduction to $\mathbf{P}^{2} \mathrm{AMF}$}

From the user perspective, $\mathrm{P}^{2} \mathrm{AMF}$ has many similarities to OCL applied to class and object diagrams. As can be seen in the derivations in Section $4, \mathrm{P}^{2} \mathrm{AMF}$ statements generally appear identical to OCL statements. However, their interpretation differs because $\mathrm{P}^{2} \mathrm{AMF}$ takes uncertainty into consideration.

In $\mathrm{P}^{2} \mathrm{AMF}$, two kinds of uncertainty are introduced. Firstly, attributes may be stochastic. For instance, when classes are instantiated, the initial values of their attributes may be expressed as probability distributions. To the attribute Actor. expenses in the following example,

context Actor: :expenses: Real

init: Normal $(3500,300)$

a normal distribution with a mean of 3500 and a standard deviation of 300 is assigned. The above expression determines the initial value of attribute instances. In the corresponding object diagrams, the values may be further specified in the form of evidence. Evidence, a term borrowed from the Bayesian theory of probabilistic inference, determines the attribute value of the instance, and may be either deterministic (hard evidence) or probabilistic (soft evidence).

Secondly, the existence of objects and links may be uncertain. It may, for instance, be the case that we do not know whether we will be able to generate solar energy next week. This can be represented as a case of object existence uncertainty (i.e., whether 
the generation activity will exist next week is not certain). Such uncertainty is specified using an existence attribute that is mandatory for all classes:

context GenerationActivity: :existence:Boolean

init: Bernoulli(0.8)

where the Bernoulli probability distribution states that there is an $80 \%$ chance that the activity in fact exists. Uncertainty with respect to the existence of links may be specified in a similar way.

The introduction of two mandatory existence attributes and the specification of attribute values by means of probability distributions thus constitute the only changes to OCL as perceived by the user. These changes, however, allow for a comprehensive probabilistic treatment of OCL-annotated class and object diagrams, including both attribute uncertainty and structural uncertainty. The mathematical approach and inference algorithms behind the approach are presented in [4]. In brief, object diagrams are subjected to Monte Carlo-based probabilistic inference with algorithms, e.g., Metropolis-Hastings [1] and Rejection Sampling [2]. Attributes with previously unknown values are assigned probability distributions. Those with known probability distributions are updated in the light of their relations to neighboring attributes as well as in the light of evidence assigned to various attributes.

With the tool support presented in Section 3.2, the analyst can perform predictive inference on object diagrams with the click of a button. The results of the inference are new probability distributions assigned to the attributes. As these are often nonparametric, they are most easily presented in the form of histograms.

\subsection{The EAAT Tool}

We have developed a software tool, the Enterprise Architecture Analysis Tool (EAAT), that allows both probabilistic class diagrams and probabilistic object diagrams to be modeled. It also performs inference as described in the previous subsection. The tool is presented in detail in [3] and can be downloaded from [32]. It is divided into two components, the CLASS MODELER, and the OBJECT MODELER, corresponding to two file types: class and object diagrams.

The CLASS MODELER is a graphical editing tool for probabilistic class diagrams. In addition to the basic editing functionality, the CLASS MODELER (i) allows attribute values to be defined either by probability distributions or by OCL expressions, (ii) requires a value for the mandatory existence attributes of classes and associations, and (iii) provides OCL syntax checking support.

The OBJECT MODELER has two components: 1) an editing tool for probabilistic object models, and 2) an inference engine. The editing tool (i) allows probabilistic attribute values, including the mandatory existence attributes, (ii) displays histograms for all attributes representing their probability distributions after inference, and (iii) offers an interface to different inference algorithms and parameters. With one click, the calculations described in Section 3.1 generate posterior probability distributions for all attributes. 


\section{$4 \quad$ Predicting Profitability Risks Using $\mathrm{e}^{3}$-Value Models and $\mathbf{P}^{2} \mathbf{A M F}$}

Due to the fact that the $\mathrm{P}^{2} \mathrm{AMF}$ and the EAAT allow us to incorporate uncertainty in $\mathrm{e}^{3}$-value models (at object, attribute and relationship levels), profitability predictions can be seen as risk assessments. Risk is generally defined as "the frequency and magnitude of loss that arises from a threat (whether human, animal, or natural event)" [25] and calculated as the threat's probability multiplied by the magnitude of its effect (i.e., the size of the value loss). Thus, our profitability calculation fits in the above definition (i.e., of profitability risk) as it takes into account both uncertainty and magnitude of the net earnings. In this section we present our approach for risk prediction.

\subsection{The $\mathrm{e}^{3}$-Value Metamodel}

As expressed in $\mathrm{P}^{2} \mathrm{AMF}$ (Figure 1), the $\mathrm{e}^{3}$-value metamodel is quite similar to the $\mathrm{e}^{3}$ value ontology presented in [21]. All metamodel entities and relations of the $\mathrm{P}^{2} \mathrm{AMF}$ version can be found in the $\mathrm{e}^{3}$-value ontology. For reasons of economy, a few concepts and relations in the $\mathrm{e}^{3}$-value ontology have been omitted in the $\mathrm{P}^{2} \mathrm{AMF}$ metamodel.

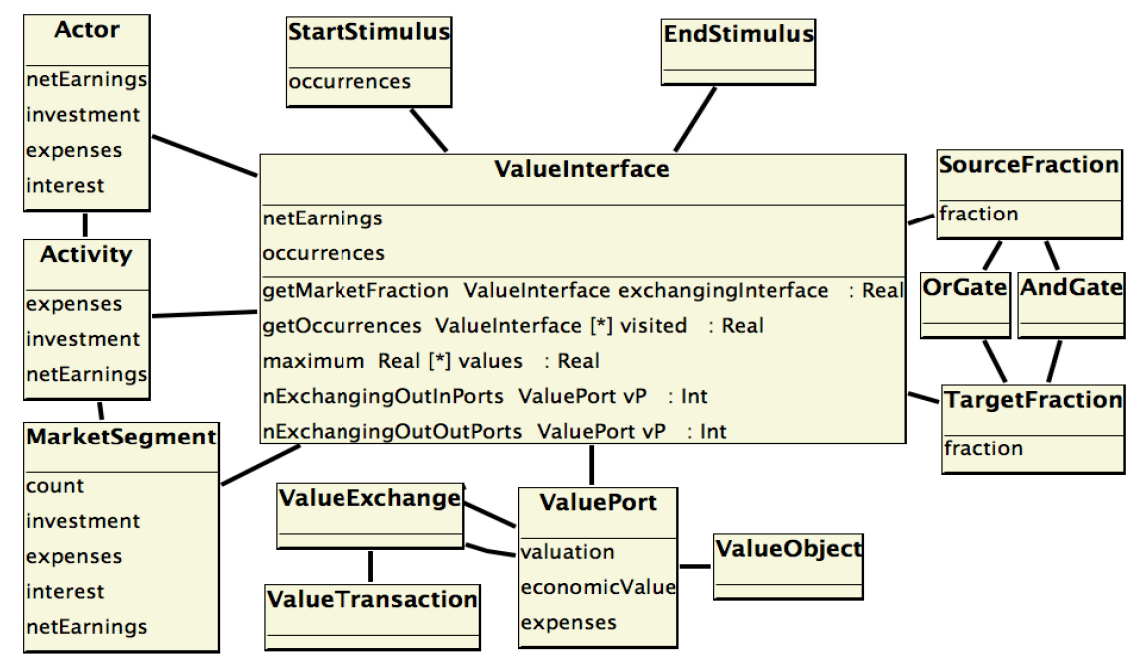

Fig. 1. $\mathrm{e}^{3}$-value metamodel

Currently, the $\mathrm{P}^{2} \mathrm{AMF}$ version does not feature composite actors. It was also possible to omit a few elements from the Use Case Maps of the $\mathrm{e}^{3}$-value ontology without affecting the profitability algorithms. A few attributes and several operations have also been added in the $\mathrm{P}^{2} \mathrm{AMF}$-based metamodel. In this section, we will focus on these attributes and operations as these contain the OCL statements used to replicate the calculations of the $\mathrm{e}^{3}$-value profitability sheet. 


\subsection{The Risk Prediction Approach}

The main goal of the profitability analysis is to calculate the net earnings of each actor. While this attribute is not explicit in the $\mathrm{e}^{3}$-value ontology or tool, it is calculated in the Excel profitability sheet generated by the tool. In the $\mathrm{P}^{2}$ AMF-based metamodel, this attribute, Actor. netEarnings, is defined as follows:

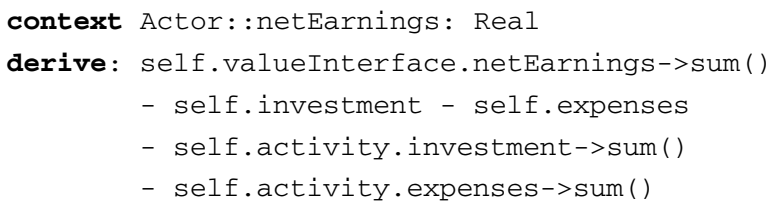

The net earnings are thus the sum of all net earnings of the actor's value interfaces minus the actor's direct investments and expenses and the investments and expenses of the actor's activities. As noted in [21], a proper net present value calculation requires a time series of $\mathrm{e}^{3}$-value models. This is also the case for the $\mathrm{P}^{2} \mathrm{AMF}-$ based version.

While investments and expenses are non-derived attributes, net earnings of value interfaces are derived.

context ValueInterface: :netEarnings: Real

derive: self.valuePort.economicValue->sum()

The net earnings of a value interface are thus the sum of the economic values of the value ports.

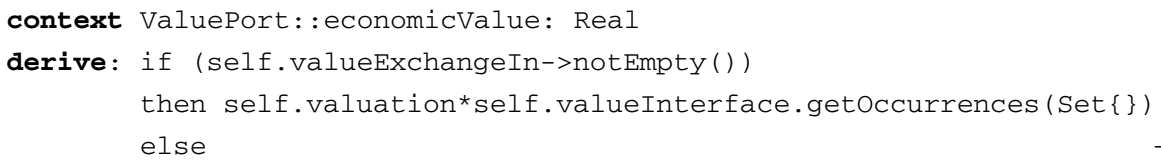

Each value port has a valuation attribute, specifying the value of the exchanged value object. If the value port is incoming, net earnings are increased by the product of the valuation attribute and the number of transactions. If the value port is outgoing, the net earnings are decreased by the corresponding amount. The occurrences, or number of transactions, originate from the attribute occurrence in the start stimulus. The value port occurrences are also affected by the structure of the use case map. For instance, if the scenario path from the start stimulus to the considered value port contains an OR fork with two branches, then the occurrences of the value port will be a fraction of those of the start stimulus. In order to calculate the occurrences of a value port, a recursive algorithm is employed. The algorithm searches through the use case map in order to find the start stimulus. The occurrence value is then propagated and transformed from value interface to value interface by various mechanisms. In many cases, the occurrence value is simply copied. In other cases, such as for the OR fork, the occurrence value is diminished by a factor determined by the fraction attributes of the SourceFraction and TargetFraction classes. 


\subsection{The Electric Cars Case Study}

The Stockholm Royal Seaport (SRS) smart city project has a vision of becoming a world class environmental city district [29]. This could include micro electricity generation by consumers and electric car usage. Our example includes both cases in one simplified scenario, in which we use pricing estimates from [28]. The scenario of the example is as follows. Electric cars used in the SRS area. The cars' owners want to maximize the usage of their resources and earn extra money with the cars when they are not in movement. They can do that by participating in the frequency control market, where electric car capacity is aggregated and sold as a resource to the transmission system operator [28]. In our scenario, the electric vehicle (EV) aggregator operates charging stations, where cars should be plugged in to the grid when idle. The micro-generators have long-term contracts with the aggregator. The example is presented as an $\mathrm{e}^{3}$-value model in Figure 2.

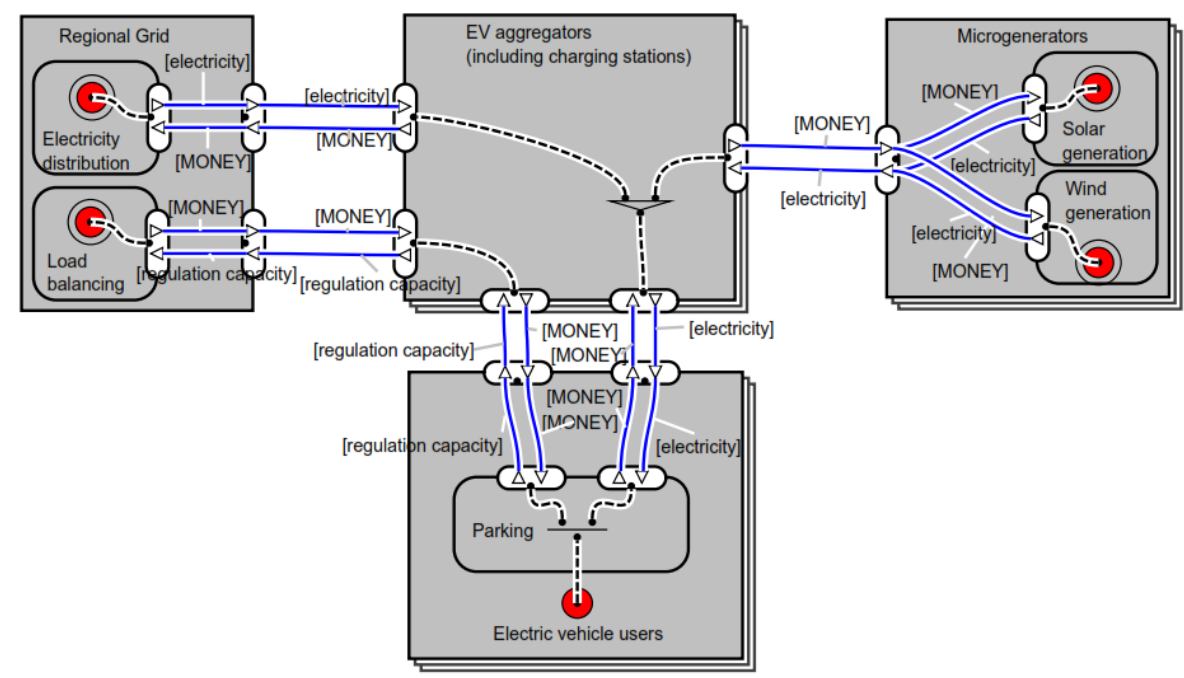

Fig. 2. The $\mathrm{e}^{3}$-value model for the electric cars case

The models depict one day. It is assumed that there are $\mathrm{B}(20000,0.5)$ cars in the neighborhood, where $\mathrm{B}$ is the binomial distribution (in this case with a mean value of 10000 ). They are assumed to have $10 \mathrm{kWh}$ batteries, needing to be charged once a day, which implies an occurrence attribute of the start stimulus with the value 1 . We further estimate the number of micro generators to $\mathrm{B}(12,0.5)$ and the number of $\mathrm{EV}$ aggregators to $\mathrm{B}(3,0.75)$. There is only one regional grid. Since we are uncertain of the future price of electricity, we estimate that the car owner pays $0.98 \pm 0.1 €$ (where 0.98 is the mean and 0.1 is the standard deviation of a normal distribution) per charging, while the price of electricity for the EV aggregator from the regional grid is $0,81 \pm 0,1 €$. Due to its long-term contract, the EV aggregator purchases electricity from the local micro generators at a fixed price of $0.58 €$, when power is available. Considering the alternatives, customers on average value one battery charging at $1,2 \pm 0,2 €$. The regional 
grid buys electricity from producers, and thus values the electricity required for one charging at $0,6 \pm 0,1 €$. As the micro generators cannot sell their electricity elsewhere, it has no value to them outside of the transaction with the EV aggregator. The local grid operator is expected to value the capacity provided by one car battery at $0.4 \pm 0.05 € /$ day, considering the available alternatives. Therefore, it makes sense to purchase that capacity for $0.32 \pm 0.05 €$ from the EV aggregator. The aggregator in turn, buys the capacity from each car owner for $0.25 \pm 0.05 €$. For the car owner, the cost of providing the regulation is low; the tapping and recharging cause some battery degradation, and there is an inconvenience finding the car with less than a full battery. Based on these considerations, the value of the capacity for the average car owner is estimated at $0.2 \pm 0.04 €$.

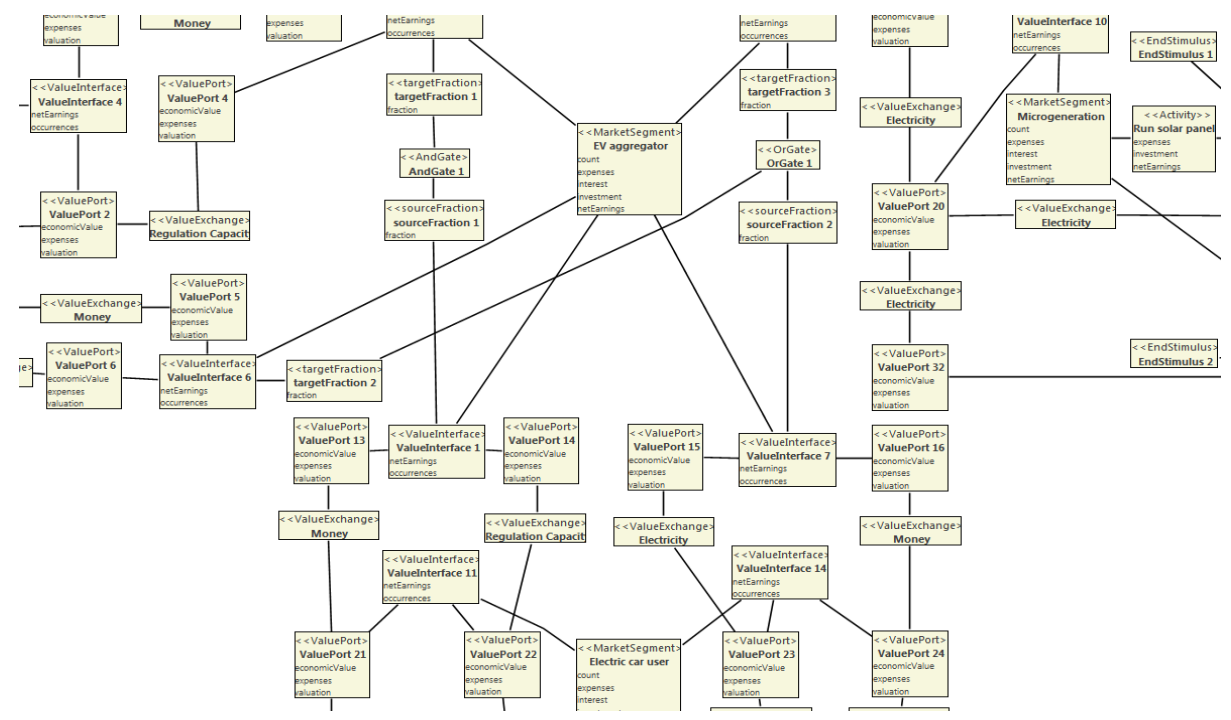

Fig. 3. The object models for the electric cars $\mathrm{e}^{3}$-value model

Considering the investment costs and expenses, EV aggregators expect fixed costs of $600 \pm 200 € /$ day, and running expenses of $500 \pm 200 € /$ day. The micro generators' fixed costs are estimated to $110 \pm 20 € /$ day with no running expenses. The regional grid has no extra costs in this business model, nor does the car owner. The $\mathrm{e}^{3}$-value profitability sheet [21] sums up all the value generated in interfaces and subtracts investment and expense costs. The calculations are further based on the number of occurrences and market segment counts. As $\mathrm{e}^{3}$-value does not consider uncertainty, mean values are utilized. According to the profitability sheet, the net earnings of each actor is the following: Regional Grid: $2270 €$ /day; EV Aggregator: $445 € /$ day; Micro-generator: $180 € /$ day. As end-customers, the electric car owners' utility is calculated to be $0,27 € /$ day. Thus, according to the $\mathrm{e}^{3}$-value model, the example is a sound business model that deserves investment from all parties. Let us now consider the $\mathrm{P}^{2} \mathrm{AMF}$-based version. In the EAAT tool, the graphical representation is a rather large object diagram, a fragment of which is shown in Figure 3. This is visually not as 
efficient as an $\mathrm{e}^{3}$-value model, but the automated model transformation between the two notations is straightforward and could be implemented. In $\mathrm{P}^{2} \mathrm{AMF}$, the above uncertainties are easily accommodated. By the Monte-Carlo sampling approach, nonparametric probability distributions are generated for all attributes.

The distributions of the net earnings of the involved actors are presented in Figure 4, Figure 5, Figure 6, and Figure 7.
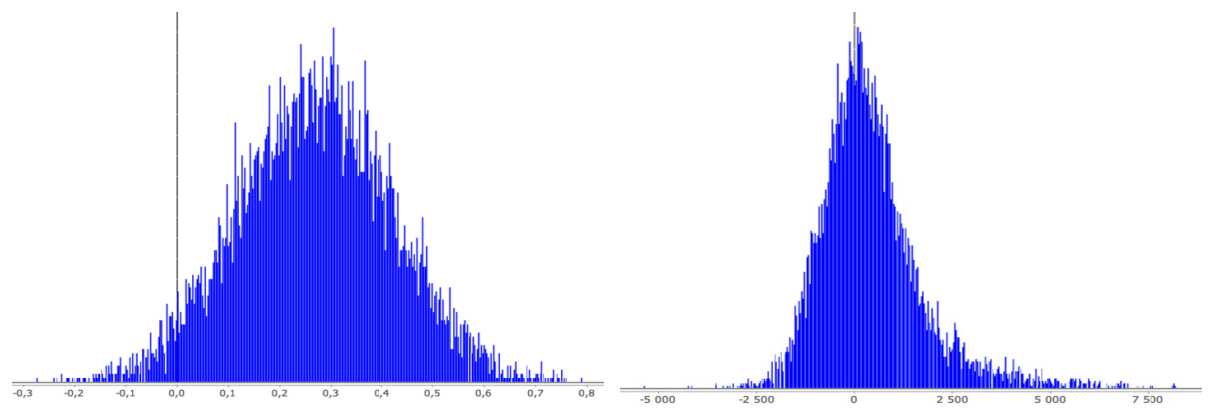

Fig. 4. Net earnings of electric car owner. Fig. 5. Net earnings of EV Aggregator. Mean Mean is $0.27 € /$ day. is $450 € /$ day.
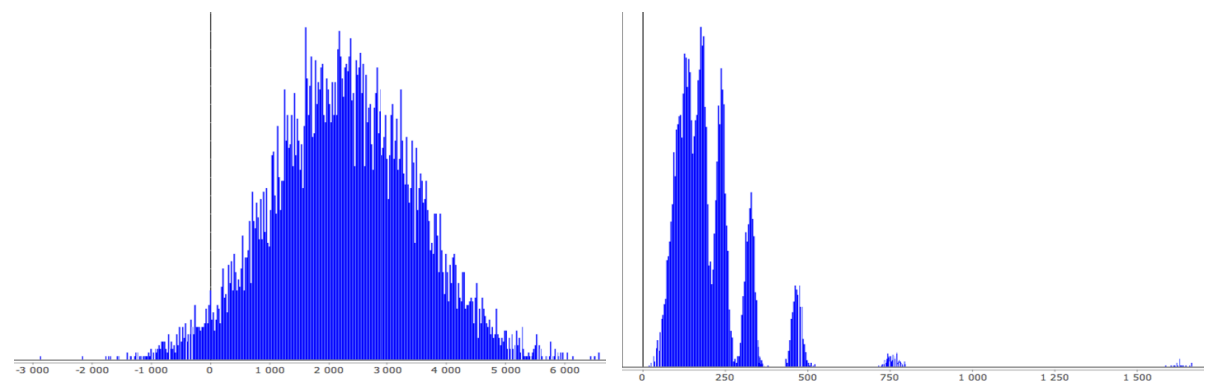

Fig. 6. Net earnings of Regional Grid. Mean is Fig. 7. Net earnings of Micro-generators. $2300 € /$ day. Mean is $210 € /$ day. The irregular shape is due to the probability of competition.

Due to the replacement of the binomial distributions with the nearest integer, we find that the net earnings' mean values of the $\mathrm{e}^{3}$-value model are slightly off. However, this error is marginal. In accordance with the $\mathrm{e}^{3}$-value results, we find that there is good reason for the Regional Grid, the Micro-generators, and the electric car owners to sign up for this business model. However, the probability distribution of the EV Aggregator is alarming. Although the mean value is positive, the probability of economic loss is very high. There seems to be a $50 \%$ chance of losing money for the EV Aggregator. Any moderately risk-averse agent should be advised against this business model. 


\section{Conclusions}

Prediction and assessment of the expected profitability and behavior of a new business venture already in the early planning phase is a desirable capability, especially in support of strategic decision making. As the business venture becomes more complex and involves more partners, the sources of risks also proliferate, which increases the criticality of analyses taking uncertainty into consideration. In this paper, we have reported on an approach and a tool for probabilistic prediction and assessment of profitability risks. The proposed formalism is based on the $\mathrm{e}^{3}$-value business modeling language and the $\mathrm{P}^{2} \mathrm{AMF}$ framework, and supports automated probabilistic reasoning based on set theory, first-order logic and algebra. Our approach allows us to anticipate profitability levels expressed as probability distributions assigned to the model elements' attributes.

The proposed approach assumes that the value network model is enriched with realistic probability distributions. However, in real situations the form of those distributions may be challenging to obtain. This lack of knowledge may have a negative impact on the quality of the analysis outcomes. To a very large extent this is due to the fact that value networks abstract from the internal details of the actors involved in the business collaboration. We argue that such quantitative input (of sufficient accuracy) can be obtained if one takes these internal details into account, and relates value network models to enterprise architecture models. Therefore, one direction in which we foresee a possible extension of our approach is that of chaining existing enterprise architecture cost analysis [31] and prediction techniques with the value network profitability prediction technique proposed in this study.

\section{References}

1. Koller, D., Friedman, N.: Probabilistic graphical models: principles and techniques (2009)

2. Walsh, B.: Markov chain monte carlo and gibbs sampling (2004)

3. Johnson, P., Johansson, E., Sommestad, T., Ullberg, J.: A Tool for Enterprise Architecture Analysis. In: Proceedings of the 11th IEEE International Enterprise Computing Conference, EDOC 2007, Annapolis, USA (2007)

4. Johnson, P., Ullberg, J., Buschle, M., Franke, U., Shahzad, K.: $\mathrm{P}^{2}$ AMF: Predictive, Probabilistic Architecture Modeling Framework. In: van Sinderen, M., Luttighuis, P.O., Folmer, E., Bosems, S. (eds.) IWEI 2013. LNBIP, vol. 144, pp. 104-117. Springer, Heidelberg (2013)

5. Gordijn, J., Osterwalder, A., Pigneur, Y.: Comparing two Business Model Ontologies for Designing e-Business Models and Value Constellations. In: Proceedings of the 18th Bled eConference: eIntegration in Action, Slovenia (2005)

6. Al-Debei, M.M., Avison, A.: Developing a unified framework of the business model concept. European Journal of Information Systems 19, 359-376 (2010)

7. Lambert, S.: A Conceptual Framework for Business Model Research. In: Proceedings of the 21st Bled eConference: eIntegration in Action. 21st Bled eConference eCollaboration: Overcoming Boundaries through Multi-Channel Interaction, Slovenia, pp. 227-289 (2008)

8. Zott, C., Amit, R., Massa, L.: The Business Model: Recent Developments and Future Research. Journal of Management 37(4), 1019-1042 (2011)

9. Kim, W.C., Mauborgne, R.: Knowing a winning business idea when you see one. Harvard Business Review 78(5), 129-138 (2000)

10. Hedman, J., Kalling, T.: The business model concept: Theoretical underpinnings and empirical illustrations. European Journal of Information Systems 12(1), 49-59 (2003) 
11. Wirtz, B.W., Schilke, O., Ullrich, S.: Strategic Development of Business Models. Implications of the Web 2.0 for Creating Value on the Internet. Long Range Planning 43, 272-290 (2010)

12. Lumpkin, G.T., Dess, G.G.: E-Business Strategies and Internet Business Models: How the Internet Adds Value. Organizational Dynamics 33(2), 161-173 (2004)

13. Morris, M., Schindehutte, M., Allen, J.: The entrepreneur's business model: toward a unified perspective. Journal of Business Research 58(6), 726-735 (2005)

14. Demil, B., Lecocq, X.: Business Model Evolution: In Search of Dynamic Consistency. Long Range Planning 43, 227-246 (2010)

15. Yunus, M., Moingeon, B., Lehmann-Ortega, L.: Building Social Business Models: Lessons from the Grameen Experience. Long Range Planning 43, 308-325 (2010)

16. Zott, C., Amit, R.: Business Model Design: An Activity System Perspective. Long Range Planning 43, 216-226 (2010)

17. OMG, Object Constraint Language, version 2.3 (2010)

18. Alberts, B.T., Meertens, L.O., Iacob, M.E., Nieuwenhuis, L.J.M.: The MOF Perspective on Business Modelling. In: Proceedings of the Second International Symposium on Business Modeling and Software Design 2012 (BMSD 2012), pp. 43-52 (2012)

19. Pateli, A.G., Giaglis, G.M.: A research framework for analysing eBusiness models. European Journal of Information Systems 13(4), 302-314 (2004)

20. Osterwalder, A.: The Business Model Ontology - a proposition in a design science approach, PhD Thesis, Université de Lausanne (2004)

21. Gordijn, J.: Value-based Requirements Engineering: Exploring Innovative e-Commerce Ideas. PhD Thesis. Vrije Universiteit Amsterdam (2002)

22. Gordijn, J., Akkermans, H.: Value based requirements engineering: Exploring innovative e-commerce idea. Requirements Engineering Journal 8(2), 114-134 (2003)

23. Iacob, M.E., Meertens, L.O., Jonkers, H., Quartel, D.A.C., Nieuwenhuis, L.J.M., van Sinderen, M.J.: From enterprise architecture to business models and back. Software \& Systems Modeling (December 2012), doi:201210.1007/s10270-012-0304-6, Print ISSN1619-1366, Online ISSN1619-1374

24. Fatemi, H., Van Sinderen, M.J., Wieringa, R.J.: Trust and business webs. In: Proceedings of the 15th IEEE International Enterprise Distributed Object Computing Conference, EDOC 2011, Helsinki, Finland, August 29-September 02, pp. 119-128. IEEE Computer Society (2011)

25. The Open Group: Technical Standard Risk Taxonomy, January, Doc. No.: C08 (2009)

26. OMG, Value Delivery Modeling Language (VDML), Doc. No. bmi/2011-05-11 (2011)

27. Geerts, L.G., McCarthy, E.W.: An Ontological Analysis of the Primitives of the ExtendedREA Enterprise Information Architecture. The International Journal of Accounting Information Systems 3, 1-16 (2002)

28. Andersson, S.-L., Elofsson, A.: Plug-in Hybrid Electric Vehicles as Control Power: Case studies of Sweden and Germany, Master Thesis, Report no: T-2008-317, Chalmers University of Technology, Göteborg, Sweden (2009)

29. Exploateringskontoret Stockholms Stad, Övergripande program för miljö och hållbar stadsutveckling i Norra Djurgårdsstaden, Stockholms Stad, Stockholm, Sweden (2010)

30. Asuncion, C.H., van Sinderen, M.J.: Pragmatic Interoperability: A Systematic Review of Published Definitions. In: Bernus, P., Doumeingts, G., Fox, M. (eds.) EAI2N 2010. IFIP AICT, vol. 326, pp. 164-175. Springer, Heidelberg (2010)

31. Iacob, M.-E., Jonkers, H.: Quantitative analysis of service-oriented architectures. International Journal of Enterprise Information Systems 3(1), 42-60 (2007)

32. EAAT tool download, http://www.kth. se/en/ees/omskolan/ organisation/avdelningar/ics/research/eat/downloads-1.46631 